\title{
Design Philosophy for Buildings' Comfort-Level Performance
}

\author{
Nanang Gunawan Wariyatno ${ }^{1,2}$, Han Ay Lie ${ }^{1}$, Fu-Pei Hsiao ${ }^{3}$, Buntara Sthenly Gan ${ }^{4, *}$ \\ ${ }^{1}$ Civil Engineering Department, Faculty of Engineering, Universitas Diponegoro, Semarang, Indonesia \\ ${ }^{2}$ Civil Engineering Department, Faculty of Engineering, Universitas Jenderal Soedirman, Purwokerto, Indonesia \\ ${ }^{3}$ National Center for Research on Earthquake Engineering, Tainan, Taiwan \\ ${ }^{4}$ Department of Architecture, College of Engineering, Nihon University, Koriyama, Japan \\ Received 15 March 2021; received in revised form 27 April 2021; accepted 28 April 2021
}

DOI: https://doi.org/10.46604/aiti.2021.7309

\begin{abstract}
The data reported by Japan Meteorological Agency (JMA) show that the fatal casualties and severe injuries are due to heavy shaking during massive earthquakes. Current earthquake-resistant building standards do not include comfort-level performance. Hence, a new performance design philosophy is proposed in this research to evaluate the quantitative effect of earthquake-induced shaking in a building. The earthquake-induced response accelerations in a building are analysed, and the response accelerations related with the characteristic property of the building are used to evaluate the number of Seismic Intensity Level (SIL). To show the indispensability of the newly proposed comfort-level design philosophy, numerical simulations are conducted to evaluate the comfort level on different floors in a building. The results show that the evaluation of residents' comfort levels should be considered in the current earthquake-resistant building design codes.
\end{abstract}

Keywords: comfort-level, seismic intensity level (SIL), quantification, earthquake, design philosophy

\section{Introduction}

Japan is susceptible to strong earthquakes and volcanic eruptions owing to its location at the junction of four active tectonic plates: the Pacific, North American, Eurasian, and Philippine plates. Since the 19th century, 20\% of the recorded strong earthquakes worldwide with a magnitude larger than six on the Richter scale have occurred in Japan [1].

The technological development of earthquake-resistant buildings in Japan started in 1891 during the Meiji era. In 1919, the first law related to the construction of earthquake-resistant buildings was issued. Japan's design codes are readjusted and renewed whenever a massive earthquake with a high number of casualties occurs. To prevent the collapse of buildings, the latest design codes require that structures should undergo plastic deformations while behaving elastically under small to moderate earthquake conditions. This new design method is effective for conserving human lives in the case of building collapse. However, it does not consider the possibility of deaths due to non-structural failure induced by vibration and shaking.

Japan's early warning technology, which was managed by Japan Meteorological Agency (JMA), has become very sophisticated based on Japan's experience with mitigating earthquake disasters. This study presents a new and universal design philosophy for quantifying shakings and vibrations during earthquakes based on the JMA method. The evaluation process involves the determination of Seismic Intensity Level (SIL) with the primary purpose of defining countermeasures or preventive actions for minimizing the number of human casualties.

* Corresponding author. E-mail address: gan.buntarasthenly@ nihon-u.ac.jp 
There is plenty of existing literature on the earthquake-resistant buildings and the mitigating earthquake disasters. However, to the best of authors' knowledge, there is no literature on evaluating the comfort-level performance of buildings against the shakings during earthquakes. During the occurrences of earthquakes, SIL values are calculated immediately from the earthquake wave information at the ground of every recording station during an earthquake. Higher floors in high-rise buildings will experience more vigorous shaking than the ground. Therefore, the present work will expand SIL's application from ground shaking to specific floors in a general building.

\section{Statistics on Human Casualties, Building Collapse, and Damage}

For 23 years (since 1996), JMA has collected data from 153 locations, including the seismic magnitude, SIL, number of human casualties, and building damage or collapse due to significant earthquakes [2-3]. Excluding the 2011 Tohoku earthquake in which the human casualties and building damage/collapse were primarily due to the tsunami, the comparison between the number of human casualties (death or injured) and the number of buildings that collapsed or were damaged are presented in Fig. 1.

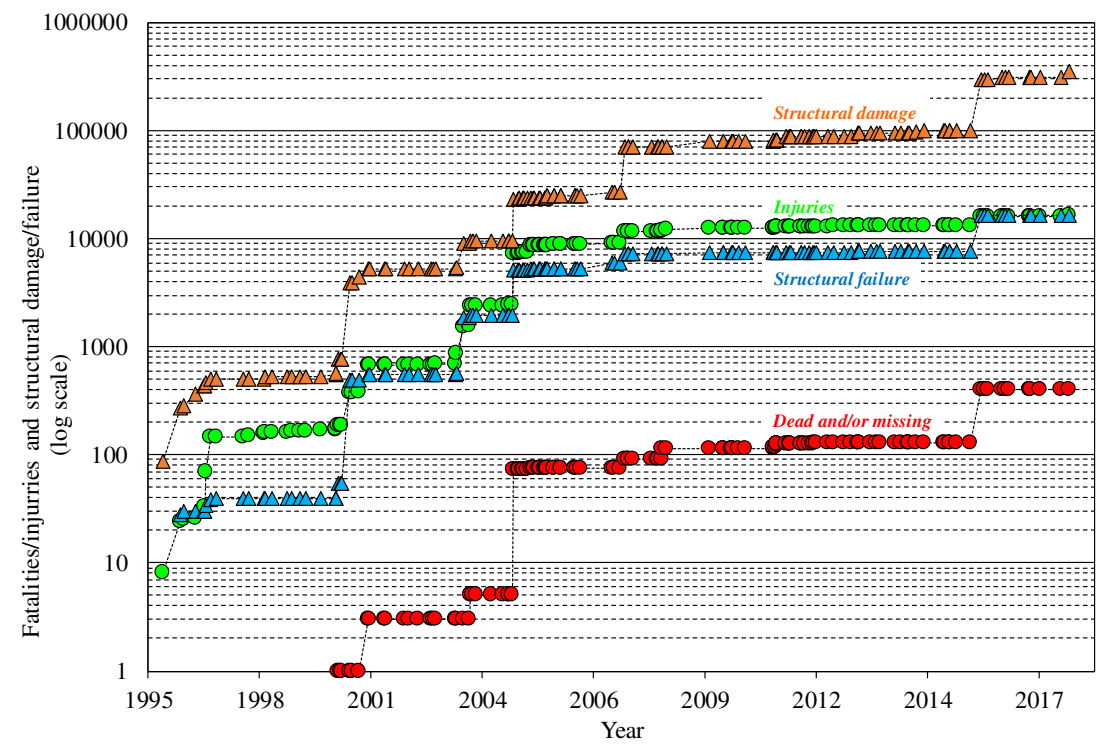

Fig. 1 Statistical data on human and building casualties due to earthquakes $[2,4]$

As shown in Fig. 1, the number of injured people is significantly larger than the number of deaths or missing people, and the ratio has increased over the years. However, the number of collapsed buildings' ratio to the number of damaged structures was far lower. The earthquake-resistant design standards provide excellent earthquake resistance in relation to just the building's strength. On the contrary, the deaths and injuries are not mainly due to building collapse [5]. Strong earthquakes that cause vibrations can result in injuries and fatalities [6-7]. Thus, structural damage plays a crucial role in the number of human casualties during earthquakes [8]. The design codes, which only focus on a structure's strength, do not suffice to protect inhabitants from injury. The behavior of buildings with the reinforced concrete subjected to lateral loads has been tested to evaluate their strengths [9-11]. The casualties attributable to the extensive shaking of a non-collapsed or damaged building should be considered. Fig. 2 shows the relationship between the earthquakes' magnitude on the Richter scale and SIL [2, 12-13].

As shown in Fig. 2, the recorded magnitudes at earthquakes' epicenters on the Richter scale and SIL deviate from their linear relationship [2, 14-15]. The non-linear relationship between the magnitudes and SIL is caused by the location of the earthquake recording stations where SIL is calculated depending on soil conditions, distances, and depths from the earthquake epicenter. Hence, the proposed new seismic-performance design code for casualties attributable to non-collapsed structures should be based on SIL values, instead of earthquakes' magnitude. SIL values provide a realistic representation of the real shaking because the effects of the building's distance from the epicenter, the soil conditions, the buildings' 
characteristics, the earthquake's magnitude, and human perceptions of the shaking phenomena due to the earthquake are considered. The quantification of human perceptions during shaking provides accurate scientific information of the buildings' residents.

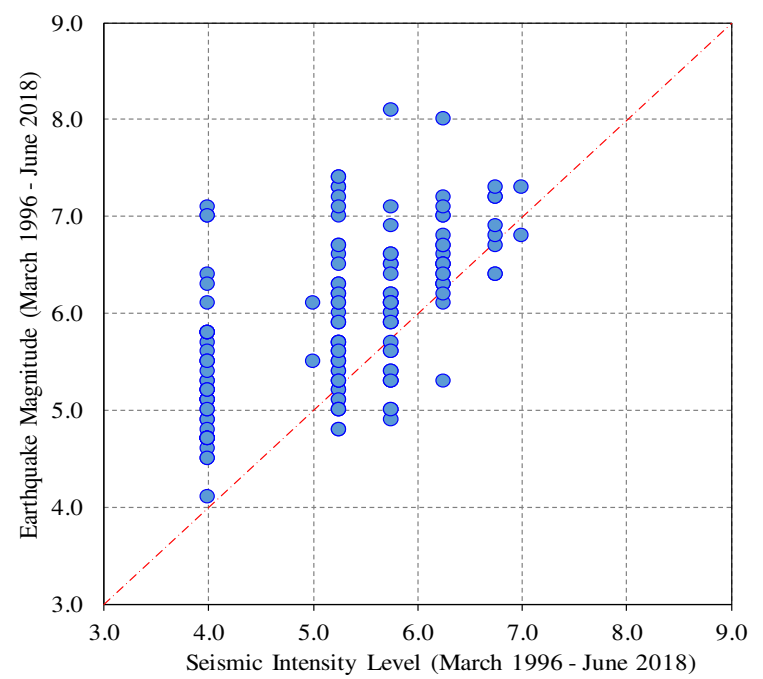

Fig. 2 Relationship between the magnitude on the Richter scale and SIL [2, 4]

\section{About SIL}

Before 1996, in Japan, SIL was qualitatively estimated based on human perceptions, and the numbers of casualties attributable to earthquakes were considered secondary information. Since then, attempts have been made to evaluate SIL quantitatively. JMA compiled the data from approximately 4000 SIL observation stations throughout Japan (recently added by Fire and Disaster Management Agency (FDMA)). SIL has been widely utilized in Japan to broadcast quick and informative earthquake warnings to the entire country through the television for disaster mitigation when an earthquake hits the country [2,16-18]. Table 1 presents the descriptions of SIL values with the corresponding SIL (computed m-SIL) ranges in 10 categories based on human perceptions and buildings' damage level.

Table 1 Descriptions of SIL (freely translated from Japanese)

\begin{tabular}{|c|c|c|}
\hline SIL & m-SIL & Human perception and reaction \\
\hline 0 & $0-0.4$ & Imperceptible to people. \\
\hline 1 & $0.5-1.4$ & Felt slightly by a few people inside a quiet room of a building. \\
\hline 2 & $1.5-2.4$ & Felt by some people inside a quiet room of a building. \\
\hline 3 & $2.5-3.4$ & Felt by most people in a building. \\
\hline 4 & $3.5-4.4$ & $\begin{array}{l}\text { Most people are startled, hanging objects such as lamps swing significantly, and unstable ornaments } \\
\text { may fall. }\end{array}$ \\
\hline $\begin{array}{c}5 \\
\text { weak }\end{array}$ & $4.5-4.9$ & $\begin{array}{l}\text { Many people are frightened and feel the need to hold onto something stable. Dishes in cupboards } \\
\text { and items on bookshelves may fall. Unsecured furniture may move, and unstable furniture may } \\
\text { topple over. }\end{array}$ \\
\hline $\begin{array}{l}5 \\
\text { strong }\end{array}$ & $5.0-5.4$ & $\begin{array}{l}\text { Many people find that it is difficult to walk without holding onto something stable. Dishes in } \\
\text { cupboards and items on bookshelves are more likely to fall. Unsecured furniture may topple over. } \\
\text { Unreinforced concrete-block walls may collapse. }\end{array}$ \\
\hline $\begin{array}{c}6 \\
\text { weak }\end{array}$ & $5.5-5.9$ & $\begin{array}{l}\text { People find that it is difficult to remain standing. Unsecured furniture moves and topples over. } \\
\text { Doors may become stuck shut. Wall tiles and windows may sustain damage and fall. In wooden } \\
\text { houses with low earthquake resistance, tiles may fall, and buildings may lean or collapse. }\end{array}$ \\
\hline $\begin{array}{l}6 \\
\text { strong }\end{array}$ & $6.0-6.4$ & $\begin{array}{l}\text { People find that it is difficult to move without crawling. People may be thrown from their position. } \\
\text { Most unsecured furniture move and are more likely to topple over. Wooden houses with a low } \\
\text { earthquake resistance are more likely to lean or collapse (compared with previous cases). Large } \\
\text { cracks may occur, as well as large landslides and collapses. }\end{array}$ \\
\hline 7 & $\geq 6.5$ & $\begin{array}{l}\text { Wooden houses with low earthquake resistance are even more likely to lean or collapse. Wooden } \\
\text { houses with a high earthquake resistance may lean. The majority of reinforced concrete buildings } \\
\text { with low earthquake resistance will collapse. }\end{array}$ \\
\hline
\end{tabular}


Additionally, Modified Mercalli Intensity (MMI) is used to classify the shaking effects on humans. Although the MMI scale has 12 intensity scales with pictorial illustrations and simple explanations regarding the effects of shaking on humans, the perceptions are essentially qualitative [19-22]. Because SIL can be evaluated quantitatively, it is an essential evaluation tool in designing buildings to reduce the seismic intensity and the number of human casualties. It should be noted that the SIL values are calculated immediately from the earthquake wave information at every recording station during the earthquake. It is most likely that higher floors in high-rise buildings will experience higher shaking SIL than the ground, hence more human casualties were due to the unmitigated design of the buildings.

\section{Calculating SIL (m-SIL)}

The procedure for computing m-SIL value (the calculated SIL value) of the JMA intensity scale was presented in [13]. A brief explanation is presented herein for clarity. First, the Fast Fourier Transform (FFT) is applied to each of the threecomponent acceleration recorded in the frequency domain of the ground responses [18]. The bandpass filters given in Eqs. (1)-(6) are then applied to the frequency domain of the three-component accelerations. After the filters are applied, the frequency domain's accelerations are transformed back to the time domain. The normalized vectored composition of the three components is used to calculate the amplitude of the acceleration. The intensity is automatically calculated using threecomponent ground acceleration records after the application of a band pass filter [13], as follows:

$$
\begin{aligned}
& \lambda=\lambda_{1} \times \lambda_{2} \times \lambda_{3} \\
& \lambda_{1}=\sqrt{\frac{1}{f}} \\
& \lambda_{2}=\sqrt{1+0.694 y^{2}+0.241 y^{4}+0.0557 y^{6}+0.009664 y^{8}+0.00134 y^{10}+0.000155 y^{12}} \\
& \lambda_{3}=\sqrt{1-e^{-8 f^{3}}} \\
& y=\frac{f}{10}
\end{aligned}
$$

where $f$ represents the dominant frequency, $\lambda_{1}$ represents the filter on-period effect, $\lambda_{2}$ represents the high-cut filter, and $\lambda_{3}$ represents the low-cut filter.

By using the filtered time-domain acceleration and its vectored acceleration, m-SIL can be determined by using Eq. (6).

$$
\mathrm{m}-\mathrm{SIL}=2 \log \left(a_{0.3}\right)+0.94
$$

where $a_{0.3}$ is the lowest maximum acceleration of a continuously total duration of 0.3 seconds around the peak acceleration response.

According to previous studies [5, 23], $a_{0.3}$ must be determined at the lowest maximum acceleration of a continuously total duration of 0.3 seconds around the absolute values of peak acceleration response. The SIL value can be classified by using the computed m-SIL value as shown in Table 1.

Fig. 3 illustrates the way to determine the $a_{0.3}$ values. Fig. 3(a) shows the band pass filtered absolute acceleration response in the time domain. The dotted line defines the lowest maximum acceleration $a_{0.3}$ of a continuously total duration of 0.3 seconds around the peak acceleration. In the second method, $a_{0.3}$ can also be determined by plotting the cumulative duration against the vectored acceleration, as shown in Fig. 3(b). The lowest maximum acceleration $a_{0.3}$ can be determined at the cumulative duration of 0.3 seconds. 


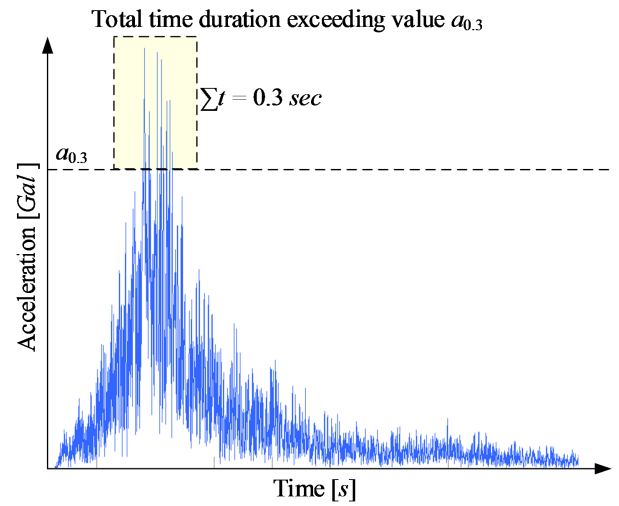

(a) FFT spectrum of response acceleration

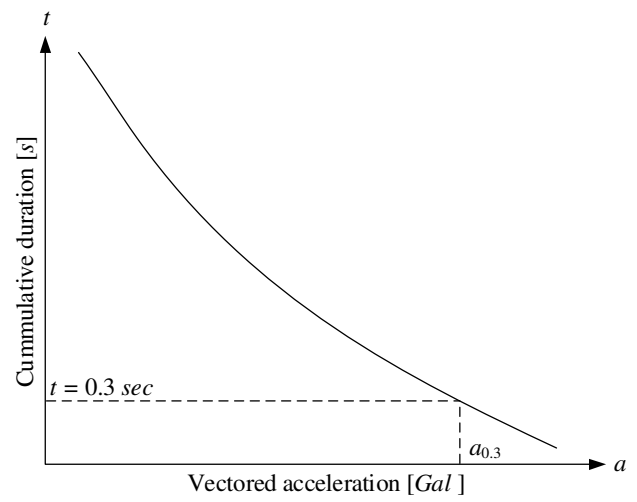

(b) Cumulative duration of FFT spectrum

Fig. 3 Illustrative response acceleration for calculating $a_{0.3}$

\subsection{Implementation of quantitative SIL in seismic-performance design}

The implementation of the quantitative values m-SIL derived from Eq. (6) should be implemented into the performance design of buildings. Fig. 4 shows a flowchart of the proposed seismic-performance design concept.

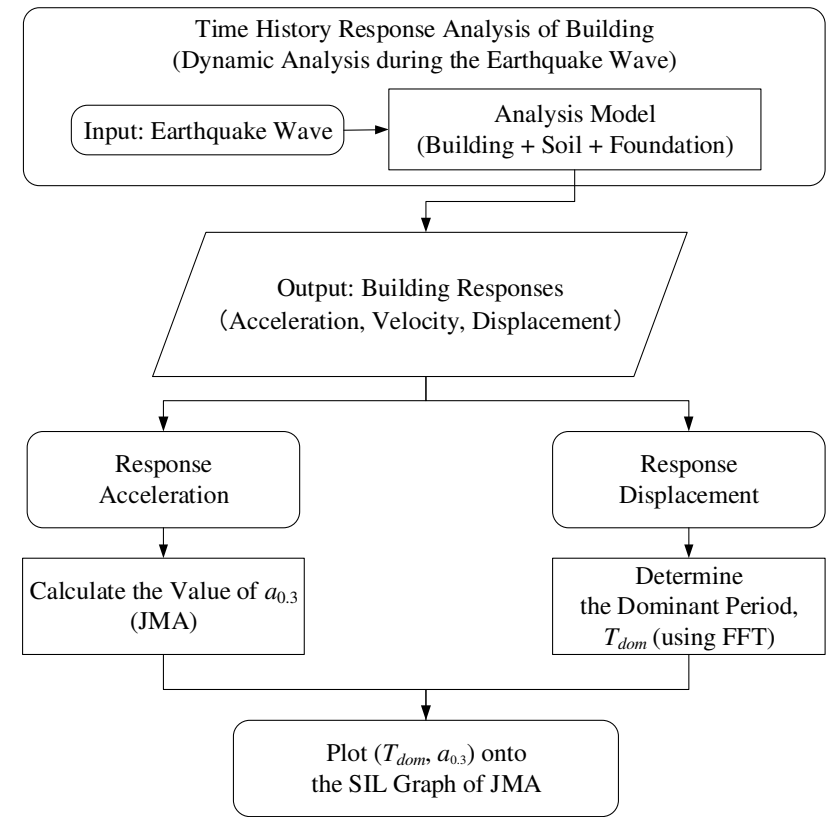

Fig. 4 Flowchart of the proposed comfort-level performance design using SIL

\subsection{Numerical simulation}

To demonstrate the effectiveness and usefulness of the proposed method, a numerical simulation is performed on a building. Numerical simulations have been proven to be a sophisticated method for evaluating the seismic performance of steel structures [24-25].

Fig. 5 shows three prototypes of a two-story steel frame structure. These three prototypes of the same structural members' steel structures are evaluated and classified according to their strengthening methods. The first structure uses Moment-Resisting Frame (MRF) method, the second structure uses concentrically Braced Frame (BRF) method, and the third structure uses MRF equipped with Base Isolation (BI) system. The columns are WF $250 \times 250 \times 8 \times 13$ sections, and the beams and bracings are WF $250 \times 125 \times 6 \times 9$ sections. All structural members are made of grade A36 steel. The span in all the directions is $4.00 \mathrm{~m}$, with a floor-to-floor height of $3.50 \mathrm{~m}$ (Fig. 5). The BI structure has a typical BI rubber bearing. The strengthening methods of the three structures are designed to fulfill the earthquake-resistant design required by the building codes. 


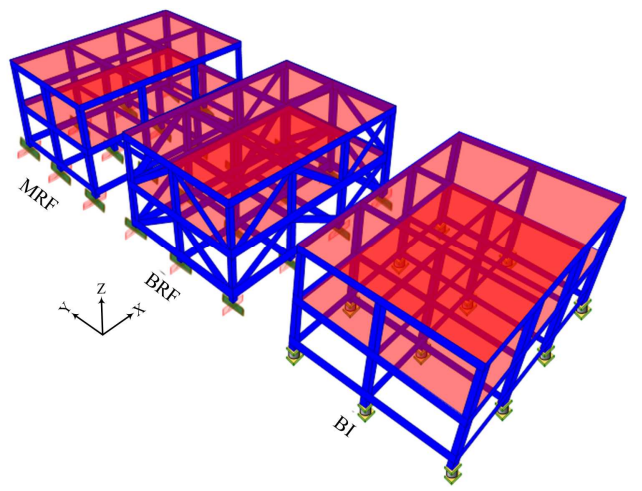

(a) Perspective view of three prototypes of two-story steel frame structures

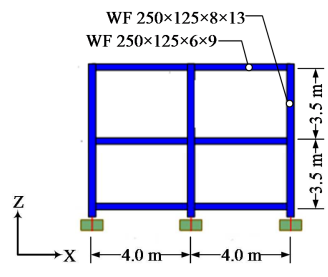

MRF

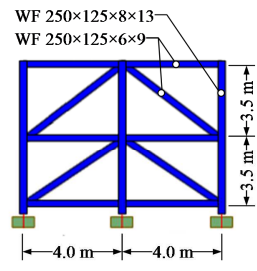

BRF

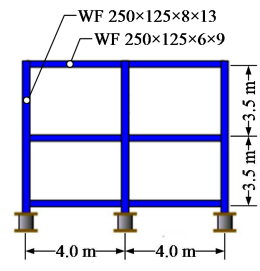

BI

(b) Three prototypes of two-story steel frame structures

Fig. 5 Types of building strengthening for SIL evaluation

The structures are assumed to be located on soft soil as this type of soil shakes the most during earthquakes. Fig. 6 shows a prior-selected response spectrum that is used to generate artificial earthquake waves. The response spectrum is obtained from Semarang (SMG), a city in Central Java $\left(7.0051^{\circ} \mathrm{S}, 110.4381^{\circ} \mathrm{E}\right)$.

In this study, several earthquake waves [26-27] recommended for seismic-performance evaluation are considered for simulation purposes. The response spectrum (Fig. 6) is used to generate artificial earthquake waves following the corresponding earthquake waves as tabulated in Table 2 . In the present numerical simulation, the earthquake waves are used for comparison purposes. To develop and check the consistency of the measured and computed signal processing of the earthquake waves, Data Consistency Assessment Function (DCAF) [28-29] is recommended.

Table 3 shows the maximum acceleration, the lowest maximum acceleration $a_{0.3}$, and the m-SIL calculated using Eq. (6) at SMG location for different earthquake waves in Table 3. It can be observed that the values of m-SIL shown in Table 3 are determined to be about 5.4 in order to fit with the selected response spectrum of SMG. The three structural prototypes are analyzed by using the linear material dynamic time-history analysis with the input earthquake waves taken from the artificial acceleration time-history as shown in Table 2.

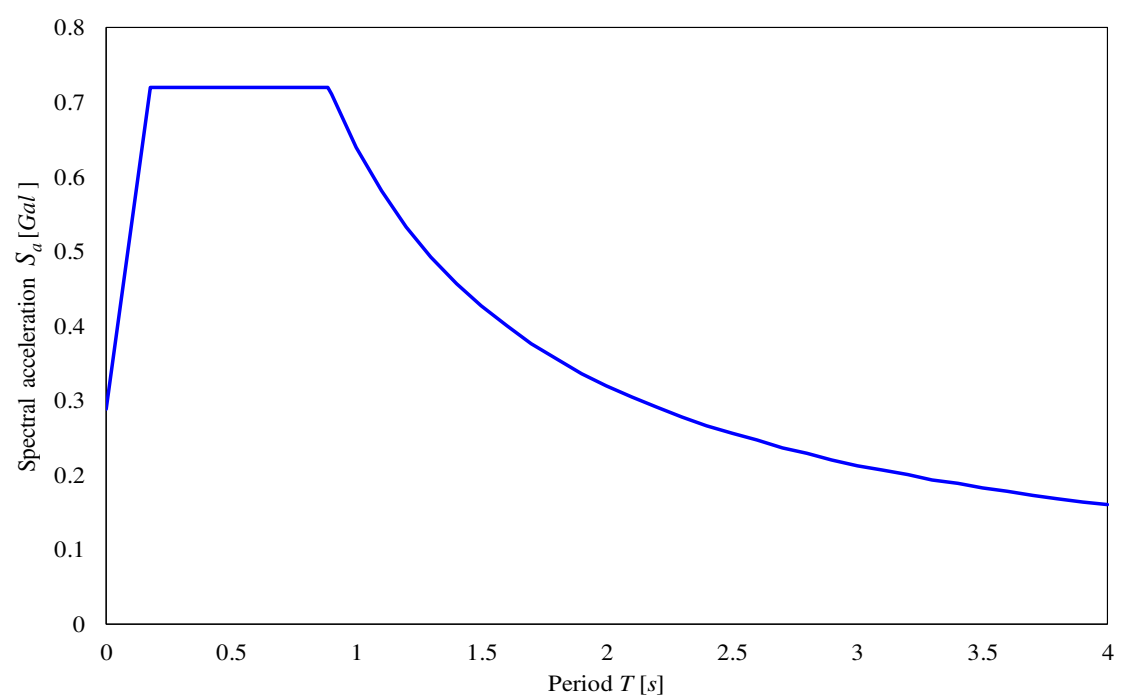

Fig. 6 Response spectrum for soft soil of SMG location 
Table 2 Artificial acceleration time-history at SMG site

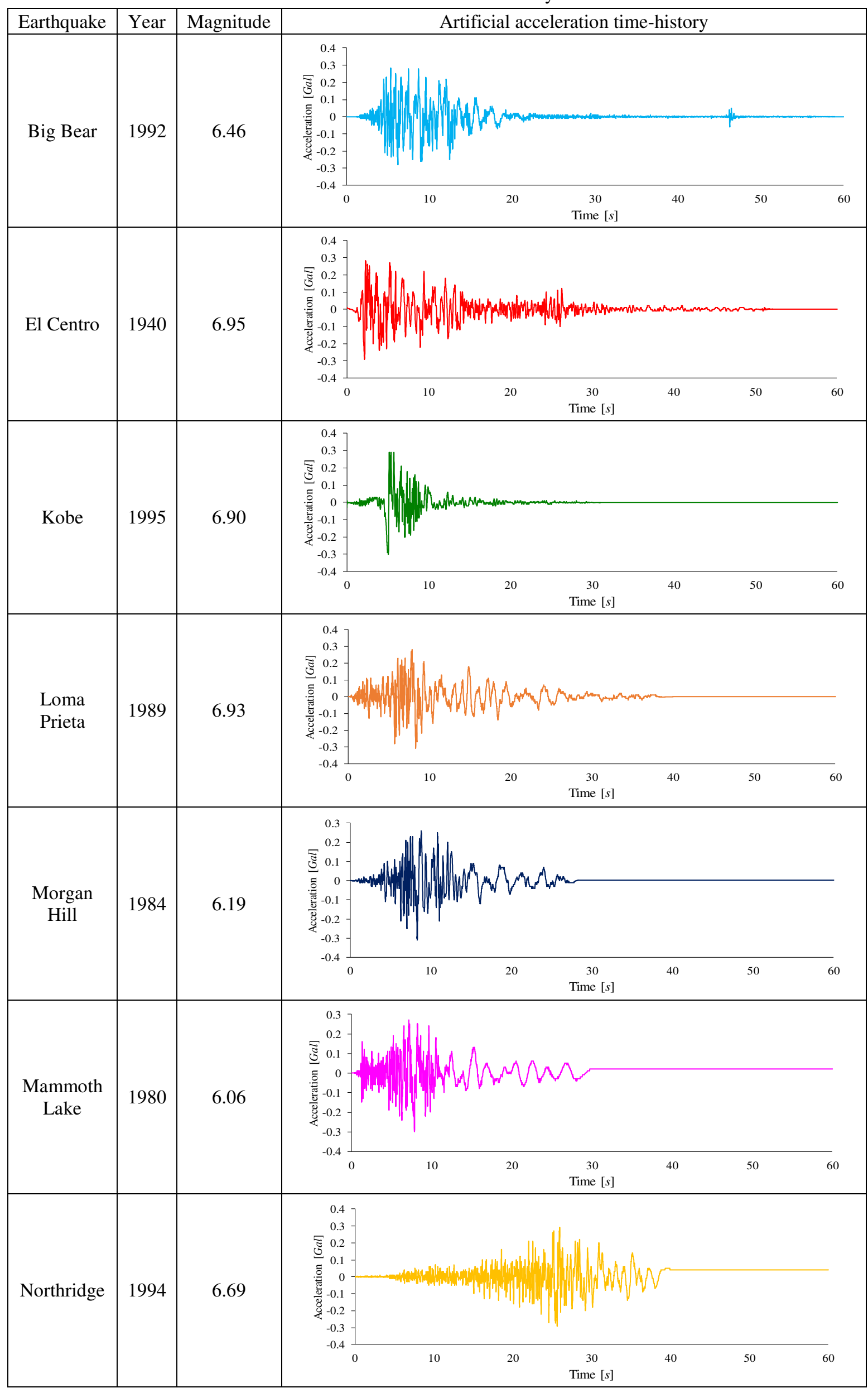


Table 3 Values of m-SIL at SMG location (ground)

\begin{tabular}{|c|c|c|c|}
\hline $\begin{array}{c}\text { Earthquake sampling } \\
\text { location }\end{array}$ & $\begin{array}{c}\text { Maximum } \\
\text { acceleration }[\mathrm{Gal}]\end{array}$ & $\begin{array}{c}\text { Lowest maximum } \\
\text { acceleration } \boldsymbol{a}_{0.3}[\mathrm{Gal}]\end{array}$ & m-SIL \\
\hline Big Bear-SMG & 280 & 178 & 5.4408 \\
\hline El Centro-SMG & 290 & 173 & 5.4161 \\
\hline Kobe-SMG & 300 & 206 & 5.5677 \\
\hline Loma Prieta-SMG & 310 & 189 & 5.4929 \\
\hline Morgan Hill-SMG & 320 & 187 & 5.4837 \\
\hline Mammoth Lake-SMG & 310 & 173 & 5.4161 \\
\hline Northridge-SMG & 290 & 166 & 5.3802 \\
\hline
\end{tabular}

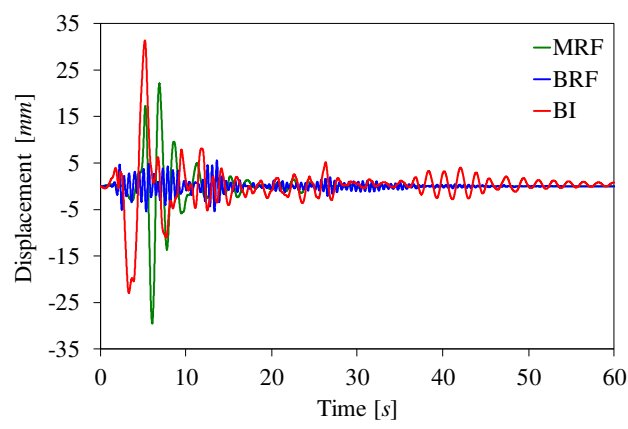

(a) Displacement-time response

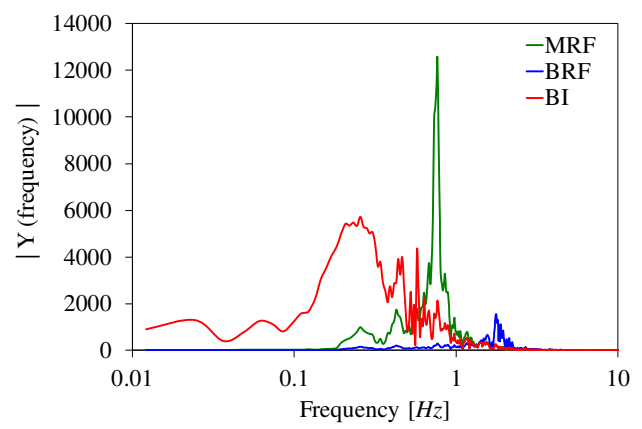

(b) FFT spectrum

Fig. 7 Rooftop response (using El Centro-SMG earthquake wave)

Table $4 T_{\text {dom }}$ calculation results using FFT

\begin{tabular}{|c|c|c|c|c|c|}
\hline \multirow{3}{*}{$\begin{array}{c}\text { Earthquake } \\
\text { sampling location }\end{array}$} & \multirow{3}{*}{ Axis } & \multirow{3}{*}{ Floor } & MRF & $\mathrm{BRF}$ & BI \\
\hline & & & $T_{\mathrm{dom}}$ & $T_{\mathrm{dom}}$ & $T_{\mathrm{dom}}$ \\
\hline & & & {$[s]$} & {$[s]$} & {$[s]$} \\
\hline \multirow{4}{*}{ Big Bear } & \multirow{2}{*}{$\mathrm{X}$} & Roof & 0.356 & 0.145 & 2.114 \\
\hline & & $2^{\text {nd }}$ & 0.356 & 0.145 & 2.114 \\
\hline & \multirow{2}{*}{ Y } & Roof & 0.475 & 0.130 & 2.048 \\
\hline & & $2^{\text {nd }}$ & 0.475 & 0.130 & 2.048 \\
\hline \multirow{4}{*}{ El Centro } & \multirow{2}{*}{$\mathrm{X}$} & Roof & 0.370 & 0.147 & 2.260 \\
\hline & & $2^{\text {nd }}$ & 0.370 & 0.147 & 2.260 \\
\hline & \multirow{2}{*}{ Y } & Roof & 0.468 & 0.127 & 2.260 \\
\hline & & $2^{\text {nd }}$ & 0.468 & 0.127 & 2.260 \\
\hline \multirow{4}{*}{ Kobe } & \multirow{2}{*}{$\mathrm{X}$} & Roof & 0.377 & 0.144 & 2.114 \\
\hline & & $2^{\text {nd }}$ & 0.377 & 0.144 & 2.114 \\
\hline & \multirow{2}{*}{ Y } & Roof & 0.471 & 0.128 & 2.114 \\
\hline & & $2^{\text {nd }}$ & 0.471 & 0.128 & 2.114 \\
\hline \multirow{4}{*}{ Loma Prieta } & \multirow{2}{*}{$\mathrm{X}$} & Roof & 0.360 & 0.148 & 2.114 \\
\hline & & $2^{\text {nd }}$ & 0.360 & 0.148 & 2.114 \\
\hline & \multirow{2}{*}{ Y } & Roof & 0.462 & 0.133 & 2.114 \\
\hline & & $2^{\text {nd }}$ & 0.462 & 0.133 & 2.114 \\
\hline \multirow{4}{*}{ Morgan Hill } & \multirow{2}{*}{$\mathrm{X}$} & Roof & 0.364 & 0.144 & 2.114 \\
\hline & & $2^{\text {nd }}$ & 0.364 & 0.144 & 2.114 \\
\hline & \multirow{2}{*}{ Y } & Roof & 0.465 & 0.124 & 2.114 \\
\hline & & $2^{\text {nd }}$ & 0.465 & 0.124 & 2.114 \\
\hline \multirow{4}{*}{ Mammoth Lake } & \multirow{2}{*}{$\mathrm{X}$} & Roof & 0.354 & 0.143 & 2.260 \\
\hline & & $2^{\text {nd }}$ & 0.354 & 0.143 & 2.260 \\
\hline & \multirow{2}{*}{ Y } & Roof & 0.478 & 0.134 & 2.185 \\
\hline & & $2^{\text {nd }}$ & 0.478 & 0.134 & 2.185 \\
\hline \multirow{4}{*}{ Northridge } & \multirow{2}{*}{$\mathrm{X}$} & Roof & 0.354 & 0.149 & 2.114 \\
\hline & & $2^{\text {nd }}$ & 0.354 & 0.149 & 2.114 \\
\hline & \multirow{2}{*}{ Y } & Roof & 0.493 & 0.132 & 2.114 \\
\hline & & $2^{\text {nd }}$ & 0.493 & 0.132 & 2.114 \\
\hline
\end{tabular}


Table 5 SIL evaluation of the rooftop floor

\begin{tabular}{|c|c|c|c|c|c|c|c|c|c|c|c|}
\hline \multirow{3}{*}{$\begin{array}{l}\text { Earthquake } \\
\text { sampling } \\
\text { location }\end{array}$} & \multirow{3}{*}{ Axis } & \multirow{3}{*}{ Floor } & \multicolumn{3}{|c|}{ MRF } & \multicolumn{3}{|c|}{ BRF } & \multicolumn{3}{|c|}{ BI } \\
\hline & & & $T_{\mathrm{dom}}$ & $a_{0.3}$ & JMA & $T_{\mathrm{dom}}$ & $a_{0.3}$ & JMA & $T_{\text {dom }}$ & $a_{0.3}$ & JMA \\
\hline & & & (s) & $(\mathrm{Gal})$ & SIL & (s) & $(\mathrm{Gal})$ & SIL & (s) & $(\mathrm{Gal})$ & SIL \\
\hline \multirow{4}{*}{ Big Bear } & \multirow{2}{*}{$X$} & Roof & \multirow{2}{*}{0.356} & 702.58 & 6 strong & \multirow{2}{*}{0.145} & 567.61 & 5 strong & \multirow{2}{*}{2.114} & 22.05 & 4 \\
\hline & & $2^{\text {nd }}$ & & 405.20 & 6 weak & & 393.82 & 5 strong & & 15.98 & 3 \\
\hline & \multirow{2}{*}{ Y } & Roof & \multirow{2}{*}{0.475} & 749.33 & 6 strong & \multirow{2}{*}{0.130} & 507.91 & 5 strong & \multirow{2}{*}{2.048} & 31.61 & 4 \\
\hline & & $2^{\text {nd }}$ & & 500.03 & 6 strong & & 367.23 & 5 weak & & 28.26 & 4 \\
\hline \multirow{4}{*}{ El Centro } & \multirow{2}{*}{$X$} & Roof & \multirow{2}{*}{0.370} & 757.04 & 6 strong & \multirow{2}{*}{0.147} & 478.93 & 5 strong & \multirow{2}{*}{2.260} & 15.30 & 3 \\
\hline & & $2^{\text {nd }}$ & & 438.34 & 6 weak & & 338.93 & 5 weak & & 14.68 & 3 \\
\hline & \multirow{2}{*}{ Y } & Roof & \multirow{2}{*}{0.468} & 702.20 & 6 strong & \multirow{2}{*}{0.127} & 475.62 & 5 strong & \multirow{2}{*}{2.260} & 26.61 & 4 \\
\hline & & $2^{\text {nd }}$ & & 433.15 & 6 weak & & 367.74 & 5 strong & & 25.64 & 4 \\
\hline \multirow{4}{*}{ Kobe } & \multirow{2}{*}{$\mathrm{X}$} & Roof & \multirow{2}{*}{0.377} & 522.19 & 6 weak & \multirow{2}{*}{0.144} & 502.98 & 5 strong & 2114 & 18.90 & 4 \\
\hline & & $2^{\text {nd }}$ & & 332.22 & 6 weak & & 340.01 & 5 strong & 2.114 & 14.87 & 3 \\
\hline & & Roof & & 700.58 & 6 strong & & 442.08 & 5 strong & & 26.64 & 4 \\
\hline & $Y$ & $2^{\text {nd }}$ & $0.4 / 1$ & 402.12 & 6 weak & 0.128 & 324.12 & 5 weak & 2.114 & 25.98 & 4 \\
\hline & $\mathrm{Y}$ & Roof & 0260 & 688.63 & 6 strong & 0118 & 512.13 & 5 strong & 2111 & 18.13 & 4 \\
\hline Loma & $\lambda$ & $2^{\text {nd }}$ & 0.300 & 422.38 & 6 weak & 0.148 & 382.89 & 5 strong & 2.114 & 16.06 & 3 \\
\hline Prieta & $Y$ & Roof & 0462 & 682.83 & 6 strong & 0133 & 468.15 & 5 strong & 2114 & 32.05 & 4 \\
\hline & & $2^{\text {nd }}$ & 0.402 & 404.61 & 6 weak & 0.155 & 344.48 & 5 weak & 2.114 & 30.43 & 4 \\
\hline & $X$ & Roof & 0364 & 770.13 & 6 strong & 014 & 475.01 & 5 strong & 2114 & 18.70 & 4 \\
\hline Morgan & $\lambda$ & $2^{\text {nd }}$ & 0.304 & 401.77 & 6 weak & 0.144 & 328.11 & 5 weak & 2.114 & 15.69 & 3 \\
\hline Hill & $\mathrm{Y}$ & Roof & 0.465 & 685.59 & 6 strong & 0124 & 439.83 & 5 strong & 2114 & 30.88 & 4 \\
\hline & 1 & $2^{\text {nd }}$ & 0.405 & 385.01 & 6 weak & 0.124 & 325.90 & 5 weak & 2.114 & 29.45 & 4 \\
\hline & $X$ & Roof & & 770.13 & 6 strong & & 531.88 & 5 strong & & 22.02 & 4 \\
\hline & $X$ & $2^{\text {nd }}$ & 0.354 & 401.77 & 6 weak & 0.143 & 367.21 & 5 weak & .260 & 15.24 & 3 \\
\hline & & Roof & & 701.33 & 6 strong & & 534.70 & 5 strong & & 26.17 & 4 \\
\hline & $Y$ & $2^{\text {nd }}$ & 0.478 & 442.03 & 6 weak & 0.134 & 381.01 & 5 weak & 2.185 & 27.35 & 4 \\
\hline & $X$ & Roof & 0354 & 687.90 & 6 strong & 0149 & 538.96 & 5 strong & 2114 & 19.89 & 4 \\
\hline North & $\Lambda$ & $2^{\text {nd }}$ & 0.534 & 406.55 & 6 weak & 0.149 & 372.79 & 5 strong & 2.114 & 16.00 & 3 \\
\hline Nortintuge & & Roof & & 764.98 & 6 strong & & 489.06 & 5 strong & & 28.86 & 4 \\
\hline & $Y$ & $2^{\text {nd }}$ & 0.493 & 456.38 & 6 weak & 0.132 & 357.85 & 5 weak & 2.114 & 28.17 & 4 \\
\hline
\end{tabular}

The displacement response on every floor in the buildings is analyzed using the time-history analysis [30] with a particular earthquake wave input. We determine the dominant period $T_{d o m}$ on every floor in the buildings from the history of displacement response. Fig. 7 shows the representative displacement responses on the rooftop of three buildings under evaluation using the El Centro-SMG earthquake wave as the input. A standard FFT is performed on the time against displacement response relationship [31-32] to determine the buildings' time dominant period (Fig. 7(a)). Fig. 7(b) presents the resulting FFT spectrum of the displacement time response of three evaluated buildings using the El Centro-SMG earthquake wave as the input. Table 4 shows the time-dominant period $T_{\text {dom }}$ based on the FFT calculation, and Table 5 presents the SIL values for each floor obtained from the lowest maximum acceleration $a_{0.3}$.

In this simulation, the rooftop floor has a higher acceleration $a_{0.3}$ than the second floor for all types of prototypes and all time-history earthquakes in both $\mathrm{X}$ - and $\mathrm{Y}$-axis directions. The acceleration is directly correlated to the SIL value. A higher $a_{0.3}$ acceleration resulted in the higher SIL value calculated from the acceleration to time-dominant period relationship is plotted in Fig. 8 [4].

The results show that the BI prototype has the lowest $a_{0.3}$ acceleration and SIL value. The SIL value ranges from 3 to 4 , corresponding to an $a_{0.3}$ in the range of 15-32 Gal. For the MRF prototype, SIL ranges from 6 weak to 6 strong, corresponding to 332-770 Gal. The BRF prototype has an $a_{0.3}$ in the range of 324-539 Gal, and SIL ranges from 5 strong to 5 weak. A graphical representation of the SIL curves as a function of the time-dominant period and maximum acceleration $a_{0.3}$ for the El Centro-SMG case is shown in Fig. 8. An examination of these graphs reveals that the range of the curve corresponds to the $a_{0.3}$ and time-dominant period ( $T_{\text {dom }}$ ) of the prototypes. 


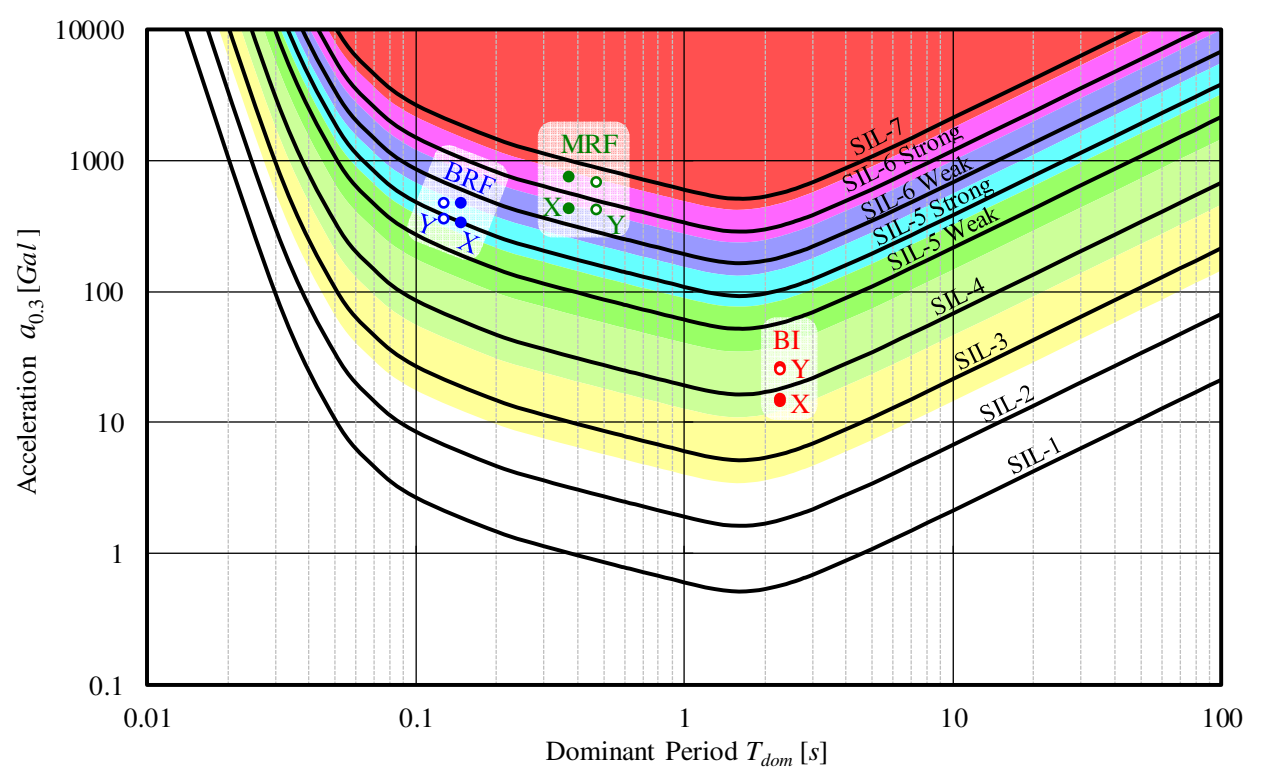

Fig. 8 SIL as a function of the dominant period and acceleration $[2,33]$

As shown in Fig. 8, the SIL values' categorization between lines is based on a more significant value than the lower SIL values. For example, for the BI frame, the X-direction response is designated as SIL-3, whereas in reality, the condition closely approaches SIL-4. Nevertheless, the classification assigns SIL to 3. This might lead to improper simulated behavior because the structure closely resembles SIL-4. It is suggested that the bandwidth between SIL categories should be proposed based on either a mathematical study or an experimental study.

The results of the numerical simulation reveal that the strengthening method significantly affects the SIL value. BI significantly reduces and stabilizes the SIL of every floor, while MRF results in a less sensitive response to SIL in all directions. Furthermore, these observations suggest that SIL is significantly affected by the frame's configuration and displacement direction, in contrast to the acceleration response.

\section{Conclusions}

A method for quantifying SIL based on the acceleration and dominant period on every floor of a structure was proposed and demonstrated. The proposed design philosophy for buildings' comfort-level performance is inherently a new and universal design philosophy that can be applied to different building codes and various earthquake waves.

One of the advantages of this SIL calculation method is that it can quantify the shaking on each floor of a building during earthquakes, which will aid the quantitative measuring of the residents' comfort levels. The proposed SIL-based performance evaluation is beneficial in the planning, designing, and strengthening stages of building constructions. The SILbased method for calculating the level of shaking can also be used to quantitatively evaluate the performance of newly developed earthquake-resistant building reinforcement equipment. Additionally, the present proposed method can monitor the shaking in buildings during earthquakes so that suitable measures can be taken quickly.

Considering the significant potential of the proposed SIL method for quantifying the level of shaking, the residents' comfort level should be accounted for in current earthquake-resistant design building codes.

\section{Future Recommendation}

Experimental works on building prototypes have to be conducted to precisely verify the quantitative shaking intensity level for research directions. For practical applications, the present proposed method could be beneficial for the following: 
(1) In the planning and designing stages, to predict the quantitative shaking that will occur in the building on different floors.

(2) In the existing stage, to characterize the quantitative shaking subjected to a specific earthquake.

(3) In the strengthening stage, to evaluate the quantitative shaking for decision making.

(4) In the research and development project stage, to quantify the level of shaking of earthquake instruments such as the base isolator, active/passive control system, and damper equipment.

\section{Conflicts of Interest}

The authors report no potential competing interests.

\section{References}

[1] "Lists, Maps, and Statistics," https://earthquake.usgs.gov/earthquakes/browse/m6-world.php, 2018.

[2] "Major Earthquakes That Occurred Near Japan (Since 1996)," www.data.jma.go.jp/svd/eqev/data/higai/higai1996new.html, 2018. (In Japanese)

[3] K. Ishibashi, "Status of Historical Seismology in Japan," Annals of Geophysics, vol. 47, no. 2-3, pp. 339-368, 2004.

[4] "Seismic Intensity and Acceleration," http://www.data.jma.go.jp/svd/eqev/data/kyoshin/kaisetsu/comp.htm, 2018. (In Japanese)

[5] H. Kawasumi, "Measures of Earthquake Danger and Expectancy of Maximum Intensity throughout Japan as Inferred from the Seismic Activity in Historical Times," Bulletin of the Earthquake Research Institute, vol. 29, pp. 469-482, 1951.

[6] S. Maruyama, Y. S. Kwon, and K. Morimoto, "Seismic Intensity and Mental Stress after the Great Hanshin-Awaji Earthquake," Environmental Health and Preventive Medicine, vol. 6, no. 3, pp. 165-169, October 2001.

[7] M. Takegami, Y. Miyamoto, S. Yasuda, M. Nakai, K. Nishimura, H. Ogawa, et al., "Comparison of Cardiovascular Mortality in the Great East Japan and the Great Hanshin-Awaji Earthquakes-A Large-Scale Data Analysis of Death Certificates," Circulation Journal, vol. 79, no. 5, pp. 1000-1008, 2015.

[8] L. A. Dengler and J. W. Dewey, "An Intensity Survey of Households Affected by the Northridge, California, Earthquake of 17 January 1994,” Bulletin of the Seismological Society of America, vol. 88, no. 2, pp. 441-462, 1998.

[9] M. Teguh, "Structural Behaviour of Precast Reinforced Concrete Frames on a Non-Engineered Building Subjected to Lateral Loads," International Journal of Engineering and Technology Innovation, vol. 6, no. 2, pp. 152-164, February 2016.

[10] W. T. Lin, T. L. Weng, and E. T. Chang, "Deterioration Estimation of Reinforced Concrete Building Structures Using Material Testing Data Base,” International Journal of Engineering and Technology Innovation, vol. 9, no. 1, pp. 22-37, January 2019.

[11] R. Hore, S. Chakraborty, A. M. Shuvon, and M. A. Ansary, "Effect of Acceleration on Wrap Faced Reinforced Soil Retaining Wall on Soft Clay by Performing Shaking Table Test," Proceedings of Engineering and Technology Innovation, vol. 15, pp. 24-34, April 2020.

[12] K. R. Karim and F. Yamazaki, "Correlation of JMA Instrumental Seismic Intensity with Strong Motion Parameters," Earthquake Engineering and Structural Dynamics, vol. 31, no. 5, pp. 1191-1212, May 2002.

[13] K. T. Shabestari and F. Yamazaki, “Attenuation Relationship of JMA Seismic Intensity Using JMA Records,” 10th Japan Earthquake Engineering Symposium, 1998, pp 529-534.

[14] A. Tan and A. Irfanoglu, "Correlation between Ground Motion Based Shaking Intensity Estimates and Actual Building Damage," 15th World Conference on Earthquake Engineering, September 2012, pp. 28588-28597.

[15] N. Gunawan, A. Han, and B. S. Gan, "Proposed Design Philosophy for Seismic-Resistant Buildings," Civil Engineering Dimension, vol. 21, no. 1, pp. 1-5, March 2019.

[16] O. Kamigaichi, "JMA Earthquake Early Warning," Journal of Japan Association for Earthquake Engineering, vol. 4, no. 3, pp. 134-137, 2004.

[17] V. Sokolov, T. Furumura, and F. Wenzel, "On the Use of JMA Intensity in Earthquake Early Warning Systems," Bulletin of Earthquake Engineering, vol. 8, no. 4, pp. 767-786, 2010.

[18] V. Y. Sokolov, "Seismic Intensity and Fourier Acceleration Spectra: Revised Relationship," Earthquake Spectra, vol. 18, no. 1, pp. 161-187, February 2002. 
[19] D. J. Dowrick, G. T. Hancox, N. D. Perrin, and G. D. Dellow, “The Modified Mercalli Intensity Scale,” Bulletin of the New Zealand Society for Earthquake Engineering, vol. 41, no. 3, pp. 193-205, September 2008.

[20] M. Grigoriu, “Do Seismic Intensity Measures (IMs) Measure Up?” Probabilistic Engineering Mechanics, vol. 46, pp. 80-93, October 2016.

[21] K. T. Shabestari and F. Yamazaki, "A Proposal of Instrumental Seismic Intensity Scale Compatible with MMI Evaluated from Three-Component Acceleration Records," Earthquake Spectra, vol. 14, no. 4, pp. 711-723, November 2001.

[22] H. O. Wood and F. Neumann, "Modified Mercalli Intensity Scale of 1931," Bulletin of the Seismological Society of America, vol. 21, no. 4, pp. 277-283, December 1931.

[23] K. Du, B. Ding, W. Bai, J. Sun, and J. Bai, "Quantifying Uncertainties in Ground Motion-Macroseismic Intensity Conversion Equations: A Probabilistic Relationship for Western China," Journal of Earthquake Engineering, vol. 24, pp. 1-25, May 2020.

[24] E. F. Deng, L. Zong, Y. Ding, Z. Zhang, J. F. Zhang, F. W. Shi, et al., "Seismic Performance of Mid-to-High Rise Modular Steel Construction-A Critical Review,” Thin-Walled Structures, vol. 155, 106924, October 2020.

[25] K. Kostinakis, I. K. Fontara, and A. M. Athanatopoulou, "Scalar Structure-Specific Ground Motion Intensity Measures for Assessing the Seismic Performance of Structures: A Review," Journal of Earthquake Engineering, vol. 22, no. 4, pp. 630-665, 2018.

[26] K. A. Porter, “An Overview of PEER's Performance-Based Earthquake Engineering Methodology,” 9th International Conference on Applications of Statistics and Probability in Civil Engineering, July 2003, pp. 1-8.

[27] Y. Chen, P. Avitabile, and J. Dodson, "Data Consistency Assessment Function (DCAF)," Mechanical Systems and Signal Processing, vol. 141, 106688, July 2020.

[28] Y. Chen, P. Avitabile, C. Page, and J. Dodson, “A Polynomial Based Dynamic Expansion and Data Consistency Assessment and Modification for Cylindrical Shell Structures,” Mechanical Systems and Signal Processing, vol. 154, 107574, 2021.

[29] Y. Chen, D. Joffre, and P. Avitabile, "Underwater Dynamic Response at Limited Points Expanded to Full-Field Strain Response," Journal of Vibration and Acoustics, vol. 140, no. 5, 051016, October 2018.

[30] M. Beer, I. A. Kougioumtzoglou, E. Patelli, and S. K. Au, Encyclopedia of Earthquake Engineering, Heidelberg: Springer Berlin Heidelberg, 2015.

[31] Y. Chen, P. Logan, P. Avitabile, and J. Dodson, "Non-Model Based Expansion from Limited Points to an Augmented Set of Points Using Chebyshev Polynomials," Experimental Techniques, vol. 43, no. 5, pp. 521-543, October 2019.

[32] S. Günay and K. M. Mosalam, "PEER Performance-Based Earthquake Engineering Methodology, Revisited," Journal of Earthquake Engineering, vol. 17, no. 6, pp. 829-858, 2013.

[33] "Seismic Intensity Level and Acceleration, Weather and Earthquakes, Seismic Intensity Information 2003," http://www.jma.go.jp/en/quake/quake_sindo_index.html, 2020.

Copyright $(\mathrm{C}$ by the authors. Licensee TAETI, Taiwan. This article is an open access article distributed under the terms and conditions of the Creative Commons Attribution (CC BY-NC) license (https://creativecommons.org/licenses/by-nc/4.0/). 